\title{
Eugenol protects cells against oxidative stress via $\mathrm{Nrf2}$
}

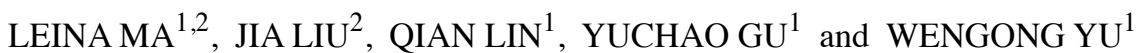 \\ ${ }^{1}$ Key Laboratory of Marine Drugs (Ministry of Education), Shandong Provincial Key Laboratory of Glycoscience and \\ Glycoengineering, School of Medicine and Pharmacy, Ocean University of China, Qingdao, Shandong 266003; \\ ${ }^{2}$ Qingdao Cancer Institute, College of Medicine, Qingdao University, Qingdao, Shandong 266021, P.R. China
}

Received July 3, 2019; Accepted March 17, 2020

DOI: $10.3892 /$ etm.2020.9539

\begin{abstract}
Eugenol is a naturally occurring compound that is present in a variety of plants and has previous been demonstrated to exert a number of bioactivities. However, the potential effects of Eugenol on cellular protection against oxidative stress remain poorly understood. In the present study, HEK-293 cells and the mouse fibroblast cell line NIH-3T3 cells were used as models to explore the effects of eugenol on $\mathrm{H}_{2} \mathrm{O}_{2}$-induced damage. Among the three natural compounds tested, namely eugenol, methyleugenol and acetyleugenol, eugenol was found to increase the transcriptional activity and expression level of nuclear factor erythroid 2-related factor 2 (Nrf2), a central regulator of cellular responses to oxidative stress, in a dose-dependent manner. The mRNA levels of Nrf2 target genes glutamate-cysteine ligase modifier regulatory subunit and glutathione S-transferase A1, were also found to be upregulated following eugenol treatment. Further study revealed that eugenol enhanced the stabilization and nuclear translocation of Nrf2. Additionally, treatment with eugenol was found to reduce intracellular ROS levels while increasing cellular resistance to $\mathrm{H}_{2} \mathrm{O}_{2}$, in a manner that was dependent on Nrf2. In conclusion, data from the present study suggest that eugenol is a protective agent against oxidative stress that exerts its effects through a Nrf2-dependent pathway, rendering eugenol and its derivatives to be promising candidates for the future development of antioxidants.
\end{abstract}

\section{Introduction}

Eugenol is the major bioactive component of clove, which has been previously documented to exhibit anti-oxidant, anti-muta-

Correspondence to: Professor Wengong Yu or Dr Leina Ma, Key Laboratory of Marine Drugs (Ministry of Education), Shandong Provincial Key Laboratory of Glycoscience and Glycoengineering, School of Medicine and Pharmacy, Ocean University of China, 5 Yushan Road, Qingdao, Shandong 266003, P.R. China

E-mail: yuwg66@ouc.edu.cn

E-mail: leinama@gmail.com

Key words: eugenol, oxidative stress, nuclear factor erythroid 2-related factor 2, reactive oxygen species genic, anti-microbial, anti-inflammatory and anti-tumor properties (1). In particular, the anti-oxidant activity of eugenol is garnering significant attention (2). Since the discovery of anti-oxidative effects of eugenol suppressed copper-mediated lipid peroxidation on erythrocyte membranes (3), analogous anti-oxidative effects of eugenol have also been documented in a number of different cell types, including hepatocytes (4), macrophages (5) and cancer cells (6). Numerous in vivo studies have also reported the ability of eugenol in eliminating reactive oxygen species (ROS), where the anti-inflammatory and anti-cancer effects of eugenol may be due to its capability in scavenging ROS $(2,5)$. Other studies have also previously suggested that the mechanism underlying the anti-oxidant activity of eugenol may involve cyclooxygenase-2 (COX-2) inhibition or direct trapping of ROS molecules $(7,8)$. Aspirin eugenol ester (AEE), synthesized by combining aspirin with eugenol, has been reported to attenuate oxidative injury of vascular endothelial cells by regulating nitric oxide synthase and Nrf2 signaling (9). However, the molecular mechanism by which eugenol suppresses the intracellular concentration of ROS and free radicals remains to be fully elucidated.

Nuclear transcription factor erythroid 2p45-related factor 2 (Nrf2) belongs to a family of basic leucine zipper protein transcription factors, which contributes to cellular defense against oxidative stress induced by external stimuli by regulating the transcription of a number of anti-oxidative factors (10). Accumulating evidence has suggested that Nrf2 serves a pivotal role in the initiation and maintenance of the protective response against oxidative stress in normal and neoplastic cells by reducing intracellular ROS levels (11). Therefore, the identification of natural Nrf2 activator is currently the topic of extensive investigation, with the aim of developing novel therapeutic interventions for diseases associated with oxidative stress (12). Curcumin, a natural product that is enriched in Curcuma longa and Oleanolic acid, an active component widely distributed in plants, have both been reported to exert anti-oxidative activity by inducing $\mathrm{Nrf} 2$ activation $(13,14)$. In addition, methyleugenol, a derivative of eugenol, has been documented to serve a protective role against tert-Butyl hydroperoxide (t-BHP)-induced cytotoxicity by activating the 5 'AMP-activated protein kinase (AMPK)/Glycogen synthase kinase $3 \beta$ (GSK3 $\beta$ ) and ERK-Nrf2 signaling pathways (15).

Therefore, the aim of the present study was to investigate the mechanism underlying the ROS-eliminating activity of eugenol and any potential effects on Nrf2 signaling. 


\section{Materials and methods}

Cell lines and reagents. 293 cells and NIH-3T3 cells were obtained from the American Type Culture Collection. Cells were cultured in DMEM supplemented with 10\% FBS, $2 \mathrm{mM}$ glutamine and $100 \mathrm{U} / \mathrm{ml}$ penicillin-streptomycin (Life Technologies; Thermo Fisher Scientific, Inc.) at $37^{\circ} \mathrm{C}$ in $5 \% \mathrm{CO}_{2}$ and were sub-cultured every 3-4 days.

Eugenol, methyleugenol, acetyleugenol, tert-butylhydroquinone (tBHQ) and diamide were purchased from Sigma-Aldrich (Merck KGaA). Nrf2 antibody was purchased from Abcam (dilution 1:1,000, cat. no. ab62352). GAPDH (dilution 1:1,000, cat. no. 2118), human influenza hemagglutinin (HA)-Tag (dilution 1:1,000, cat. no. 3724), lamin A/C (dilution 1:1000, cat. no. 2032) and cleaved caspase-3 (dilution 1:1,000, cat. no. 9664) antibodies were purchased from Cell Signaling Technology, Inc.

Plasmids. The NC16 pcDNA3.1 FLAG NRF2 plasmid was a gift from Professor Randall Moon (cat. no. 36971; Addgene, Inc.). A total of $1 \mu \mathrm{g}$ plasmid was used per transfection reaction in a 60-mm dish. The pGV113-shNRF2 and pGV113-shControl were purchased from Shanghai GeneChem Co., Ltd. A total of $1 \mu \mathrm{g}$ plasmid was used per transfection reaction in a 60-mm dish. Short hairpin sequence targeting the Nrf2 coding region was 5'-AGCAAACAAGAGATGGCAA-3', which was the sequence incorporated into the pGV113-shNRF2 plasmid. Construction of the plasmid-antioxidant responsive element (pARE)-TI-luciferase reporter (ARE-luciferase) plasmid was performed according to protocols previously described $(16,17)$. The original backbone plasmid is pGL3 Luciferase Reporter Vectors (Promega Corporation). A total of 200 ng plasmid was used per transfection reaction in 24-well plates. HA-ubiquitin was a gift from Edward Yeh (car. no. 18712; Addgene, Inc.). A total of $1 \mu \mathrm{g}$ HA-ubiquitin was used per transfection reaction in a $60-\mathrm{mm}$ dish.

ARE-derived luciferase activity assay. The construction of pARE-TI-luciferase reporter (ARE-luciferase) was completed as previously described (16,17). 293 cells or NIH-3T3 cells ( $2 \times 10^{5}$ cells per well in 24 -well plates) were transfected with the Renilla, which was used for normalizing all luciferase activity (Promega Corporation) and ARE-luciferase plasmids using Lipofectamine $^{\circledR} 2000$ (Invitrogen; Thermo Fisher Scientific, Inc.). The cells were lysed $24 \mathrm{~h}$ after transfection and assayed for luciferase activity using Dual-Luciferase ${ }^{\circledR}$ Assay system (Promega Corporation) according to the manufacturer's protocols. Relative light units were measured using a SpectraMax M5 microplate reader (Molecular Devices, LLC).

Reverse transcription-quantitative PCR (RT-qPCR). Total cellular RNA was isolated using RNeasy Mini Kit (Qiagen China Co., Ltd.), following which cDNA was synthesized using SuperScript IV Reverse Transcriptase (Invitrogen; Thermo Fisher Scientific, Inc.) according to the manufacturer's protocol. qPCR was performed in a ABI 7500 Real-Time PCR system (Applied Biosystems; Thermo Fisher Scientific, Inc.) using FastStart SYBR ${ }^{\circledast}$ Green Master (Sigma-Aldrich; Merck $\mathrm{KGaA}$ ) according to the manufacturer's protocols at the following thermocycling conditions: Initial denaturation at
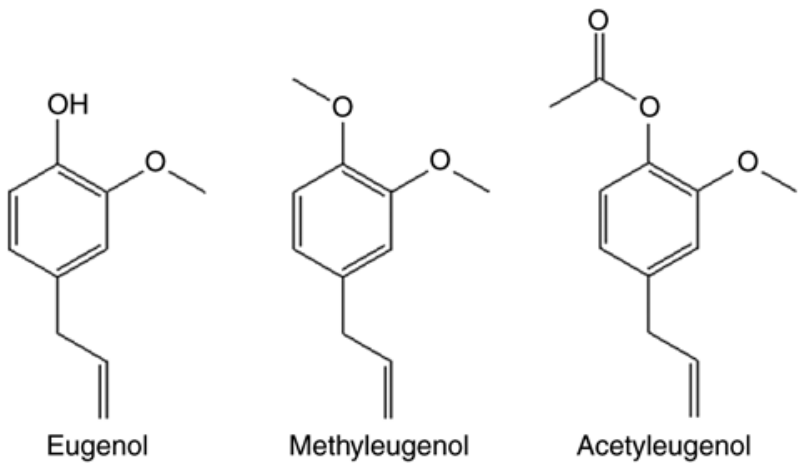

Figure 1. Chemical structure of the eugenol and its other two derivatives. The chemical structures of eugenol, methyleugenol, and acetyleugenol are presented to indicate the differences in their constitutions.

$95^{\circ} \mathrm{C}$ for $15 \mathrm{sec}$, annealing at $60^{\circ} \mathrm{C}$ for 40 cycles and extension at $72^{\circ} \mathrm{C}$ for $30 \mathrm{sec}$. Primer sequences used were as follows: NRF2-forward, 5'-AACCAGTGGATCTGCCAACTACTC-3' and reverse, 5'-CTGCGCCAAAAGCTGCAT-3'; glutamate-cysteine ligase modifier regulatory subunit (GCL-M) forward, 5'-GCTGTATCAGTGGGCACAG-3' and reverse, 5'-CGCTTGAATGTCAGGAATGC-3'; glutathione S-transferase A1 (GSTA1) forward, 5'-CCTGCCTTTGAA AAAGTCTTAAAG-3' and reverse, 5'-AAGTTCCACCA GGTGAATGTCA-3' and GAPDH forward, 5'-GGGAAG GTGAAGGTCGGAGT-3' and reverse, 5'-TGTAGTTGAGGT CAATGAAGGGG-3'. All reactions were performed in triplicate, and repeated at least twice.

Western blotting. Following treatments, 293 cells or NIH-3T3 cells were washed with ice-cold PBS and harvested using RIPA lysis buffer (Thermo Fisher Scientific, Inc.) containing protease inhibitors (Roche Diagnostics). Cell lysates were vigorously vortexed, homogenized in an ultrasonicator at $15-25 \mathrm{kHz}$ for $10 \mathrm{sec}$ and left on ice for $30 \mathrm{~min}$. The homogenates were centrifuged at $12,000 \mathrm{x}$ g for $15 \mathrm{~min}$ at $4^{\circ} \mathrm{C}$. The supernatant was subsequently collected and equal amounts $(30 \mu \mathrm{g})$ of total protein per sample, as determined by Bicinchoninic Acid protein assay (Pierce; Thermo Fisher Scientific, Inc.), was mixed with $4 \mathrm{X}$ loading buffer and heated at $95^{\circ} \mathrm{C}$ for $5 \mathrm{~min}$. The samples were then separated by $7.5 \%$ SDS-PAGE at $120 \mathrm{~V}$ and transferred onto polyvinylidene difluoride membranes (Immobilon-P; EMD Millipore) for $1.5 \mathrm{~h}$. The membranes were blocked with 5\% BSA (Sigma-Aldrich; Merck KGaA) dissolved in $1 \mathrm{X}$ TBS- $0.1 \%$ Tween 20 buffer for $1 \mathrm{~h}$ at room temperature and incubated with indicated primary antibodies overnight at $4^{\circ} \mathrm{C}$. Following primary antibody incubation, the membranes were washed three times with TBST before being incubated with the following secondary antibodies: Goat anti-mouse immunoglobulin $\mathrm{G}(\mathrm{IgG})$-horseradish peroxidase (HRP) (1:3,000; cat. no. sc-2005; Santa Cruz Biotechnology, Inc.) and goat anti-rabbit IgG-HRP (1:3,000; cat. no. sc-2004; Santa Cruz Biotechnology, Inc.) for $1 \mathrm{~h}$ at room temperature and then washed with TBST 3 times. Protein bands were visualized using SuperSignal ${ }^{\mathrm{TM}}$ West PICO (Pierce; Thermo Fisher Scientific, Inc.) followed by exposure to X-ray films, where exposure scans varied from $5 \mathrm{sec}$ to $60 \mathrm{~min}$. Quantitative data normalized against the reference gene (GAPDH for most 
A

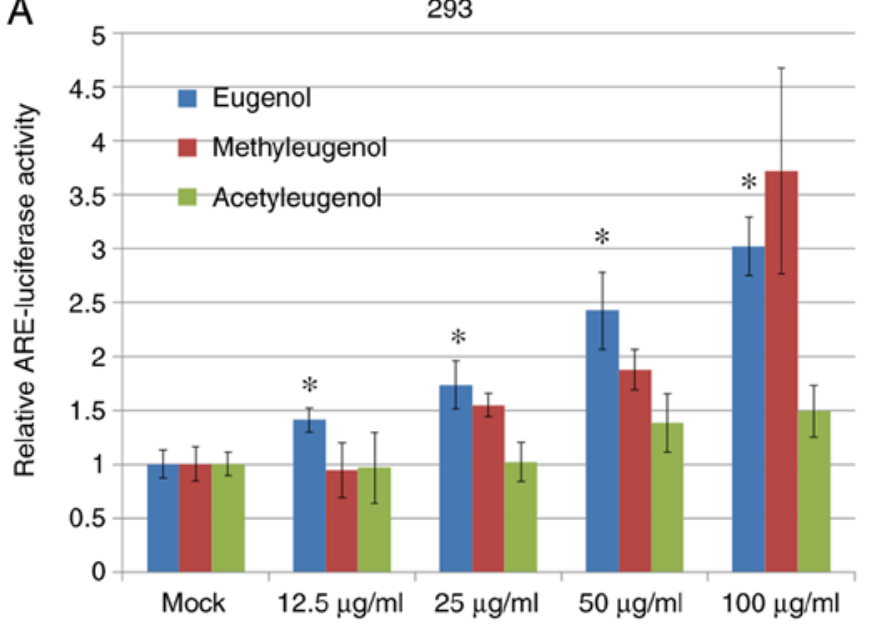

B

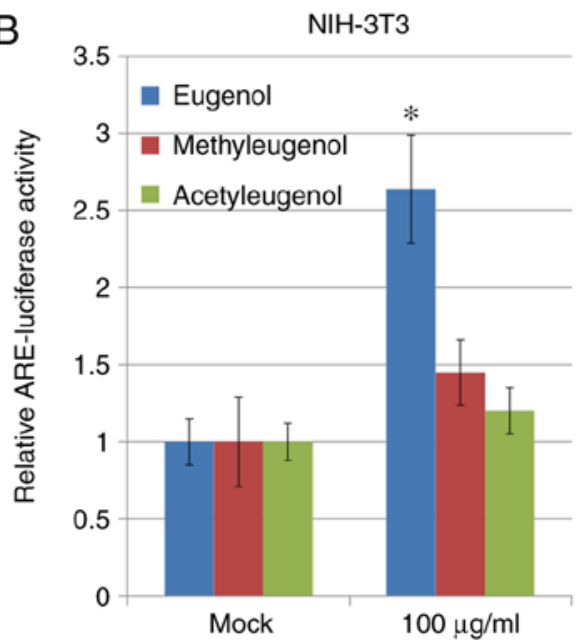

Figure 2. Eugenol promotes the transcriptional activity of Nrf2 in 293 and NIH-3T3 cells. (A) 293 cells were treated with eugenol and its derivatives at the indicated concentrations. ARE luciferase reporter assay was performed $6 \mathrm{~h}$ later to measure the transcriptional activity of Nrf2. (B) A similar experiment was performed in NIH-3T3 cells treated with $100 \mu \mathrm{g} / \mathrm{ml}$ eugenol, methyleugenol or acetyleugenol. Data are presented as mean $\pm \mathrm{SD}$. "P<0.05 vs. Mock. Nrf2, nuclear factor erythroid 2-related factor 2; ARE, antioxidant responsive element.

B

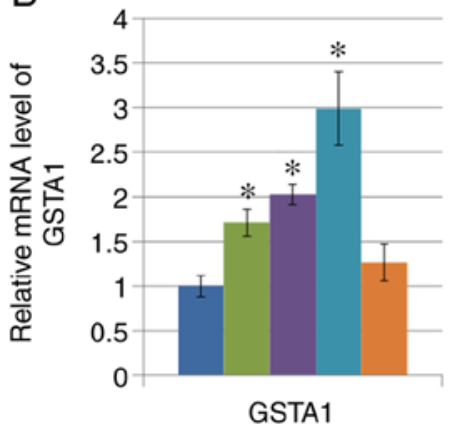

\section{A}

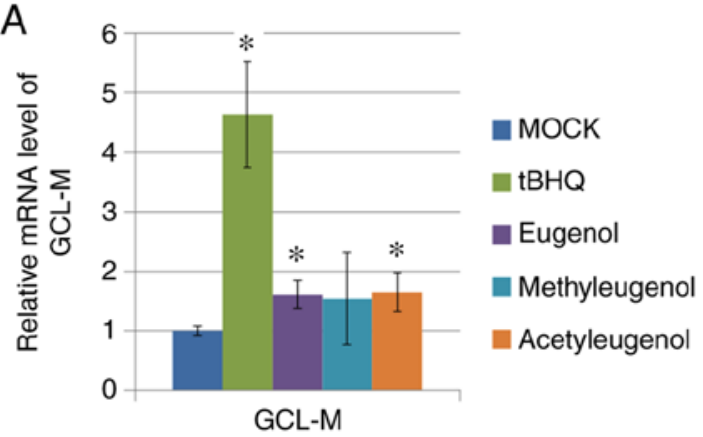

口MOCK

IBHQ

Eugenol

Methyleugenol

acetyleugenol

C

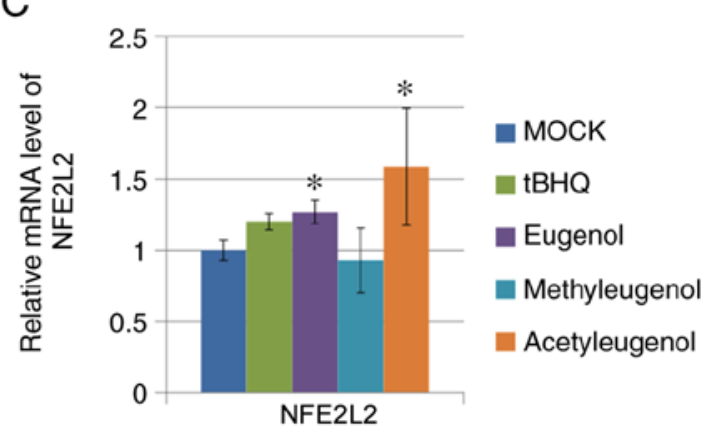

Figure 3. Eugenol enhanced the expression levels of Nrf2 target genes in 293 cells. (A) After $24 \mathrm{~h}$ treatment with $50 \mu \mathrm{g} / \mathrm{ml}$ eugenol and its two derivatives, mRNA expression of GCL-M and (B) GSTA1, target genes for Nrf2, was quantified by reverse transcription-quantitative PCR. (C) mRNA expression of NFE2L2, as measured by reverse transcription-quantitative PCR, after treatment with $50 \mu \mathrm{g} / \mathrm{ml}$ eugenol and its two derivatives. In all instances, $50 \mu \mathrm{g} / \mathrm{ml}$ tBHQ was applied as positive control. Data are presented as mean $\pm \mathrm{SD}$ from three independent experiments. "P<0.05 vs. Mock. Nrf2, nuclear factor erythroid 2-related factor 2; GCL-M, glutamate-cysteine ligase modifier regulatory subunit; GSTA1, glutathione S-transferase A1; tBHQ, tert-butylhydroquinone.

samples and lamin $\mathrm{A} / \mathrm{C}$ for nuclear samples) were obtained by densitometric analysis using the Bio-Rad Quantity One software (version 4.6.2; Bio-Rad Laboratories, Inc.).

Nrf 2 half-life experiments. 293 cells or NIH-3T3 cells (seeded into 6-well plates at $3 \times 10^{5}$ cells/well) were transfected with the NC16 pCDNA3.1 FLAG NRF2 plasmid using Lipofectamine $^{\circledR} 2000$ (Invitrogen; Thermo Fisher Scientific, Inc.). At $24 \mathrm{~h}$ following transfection, the cells were incubated with either vehicle or three eugenol derivatives for $6 \mathrm{~h}$ before being treated with $30 \mu \mathrm{g} / \mathrm{ml}$ cycloheximide (Sigma-Aldrich; Merck-KGaA), a protein synthesis inhibitor. Cells were harvested for analysis at $0,5,15$ and $20 \mathrm{~min}$.

Ubiquitination assay. 293 cells (seeded into 6-well plates at $3 \times 10^{5}$ cells/well) were co-transfected with pcDNA3.1 expression vectors encoding HA-ubiquitin and Nrf2 using Lipofectamine ${ }^{\circledR} 2000$ (Invitrogen; Thermo Fisher Scientific, Inc.). At $24 \mathrm{~h}$ following transfection, the cells were treated with eugenol at $50 \mu \mathrm{M}$ and MG132 at a final concentration of 
A

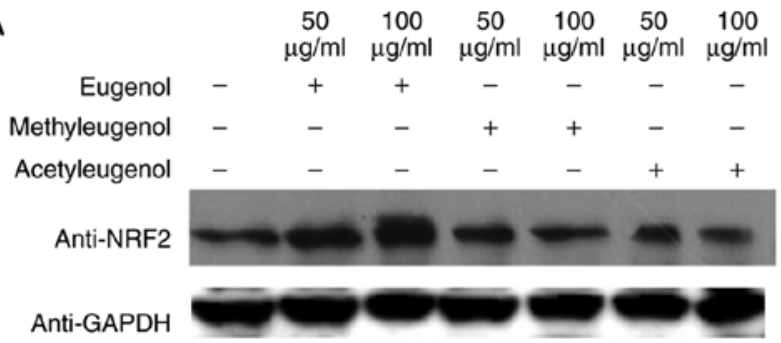

293

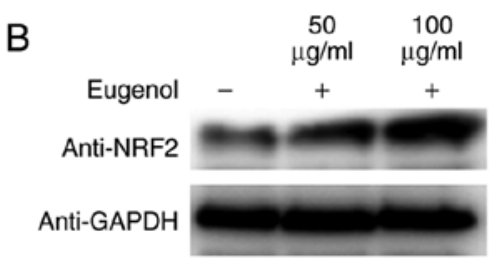

$\mathrm{NIH}-3 \mathrm{~T} 3$

Figure 4. The content of Nrf2 protein expression was increased by eugenol. (A) 293 cells were incubated with eugenol, methyleugenol or acetyleugenol (50 or $100 \mu \mathrm{g} / \mathrm{ml}$ ) for $24 \mathrm{~h}$, followed by western blotting. (B) Nrf2 protein expression level was examined by western blotting in NIH-3T3 cells following treatment with $100 \mu \mathrm{g} / \mathrm{ml}$ eugenol. Experiments were performed in triplicate. Nrf2, nuclear factor erythroid 2-related factor 2.

$2 \mu \mathrm{M}$ (Sigma-Aldrich; Merck $\mathrm{KGaA}$ ) for $12 \mathrm{~h}, 37^{\circ} \mathrm{C}$ to inhibit proteasome activity. Whole-cell extracts were subsequently prepared by lysis with RIPA buffer and subjected to purification procedures. A total of $20 \mu \mathrm{l}$ agarose beads coupled with anti-FLAG antibody (1:1,000; cat. no. F3165; Sigma-Aldrich; Merck KGaA) was added to the cell lysates and incubated with gentle agitation for $1-3 \mathrm{~h}$ at $4^{\circ} \mathrm{C}$. The lysates were microcentrifuged at 7,000 x g for 30 seconds at $4^{\circ} \mathrm{C}$. Subsequently, the pellet was washed 5 times on ice with $500 \mu 1$ 1X RIPA buffer. Precipitates were visualized by western blot analysis using the aforementioned anti-HA antibodies.

Cytoplasmic and nuclear protein extraction. 293 cells with pcDNA3.1-Nrf2 or empty pcDNA3.1 plasmid were treated with eugenol $(50 \mu \mathrm{g} / \mathrm{ml})$, tBHQ $(100 \mu \mathrm{g} / \mathrm{ml})$ or diamide $(20 \mu \mathrm{g} / \mathrm{ml})$ at $37^{\circ} \mathrm{C}$ for $6 \mathrm{~h}$. Cytoplasmic and nuclear protein were extracted using NE-PER ${ }^{\mathrm{TM}}$ Nuclear and Cytoplasmic Extraction Reagents (Pierce; Thermo Fisher Scientific, Inc.), according to the manufacturer's protocol.

ROS detection. HEK-293 cells or NIH-3T3 cells were seeded into 6-well plates at a density of $3 \times 10^{5}$ cells/well in fully supplemented DMEM for $24 \mathrm{~h}$ before they were treated with $50 \mu \mathrm{g} / \mathrm{ml}$ eugenol for $6 \mathrm{~h}$ at $37^{\circ} \mathrm{C}$. Untreated and eugenol-treated cells were subsequently harvested in fully supplemented DMEM, centrifuged for $5 \mathrm{~min}$ at $200 \mathrm{x} \mathrm{g}$ and $4^{\circ} \mathrm{C}$ and suspended in Dulbecco's PBS (DPBS) containing the $10 \mu \mathrm{M}$ CM-H2DCFDA dye (Invitrogen; Thermo Fisher Scientific, Inc.) with or without $50 \mu \mathrm{M} \mathrm{H}_{2} \mathrm{O}_{2}$, at $37^{\circ} \mathrm{C}$ in the dark for $30 \mathrm{~min}$. The cells were then pelleted and resuspended in ice-cold DPBS prior to the addition of propidium iodide $(1 \mu \mathrm{g} / \mathrm{ml})$ to the cells for $5 \mathrm{~min}$ at room temperature, for analysis by flow cytometry (MoFlo ${ }^{\circledR}$ flow cytometer; Beckman Coulter, Inc.) by measuring fluorescence emission at $525 \mathrm{~nm}$ (PI) following excitation at $488 \mathrm{~nm}$ (DCFDA/FITC). Since live cells are impermeant to propidium iodide, only cells negative for propidium iodide staining were assessed for ROS production. Data was analyzed by Kaluza C Analysis software 2.1 (Beckman Coulter, Inc.).

Cell viability. 293 cells or NIH-3T3 cells were transfected with shRNA in 60-mm dishes. At $12 \mathrm{~h}$ after transfection, cells were seeded into 96 -well plates $\left(1 \times 10^{3}\right.$ cells per well in a 96-well plate. 293 cells were treated at $37^{\circ} \mathrm{C}$ with eugenol $(0$, $25,50$ or $100 \mu \mathrm{g} / \mathrm{ml})$ and $\mathrm{H}_{2} \mathrm{O}_{2}(0,50,100$ or $250 \mu \mathrm{M})$ for $24 \mathrm{~h}$, while NIH-3T3 cells were treated with $100 \mu \mathrm{g} / \mathrm{ml}$ eugenol.
Before absorbance measurement, cells were washed with PBS followed by the addition of MTT ( $1 \mathrm{mg} / \mathrm{ml} / \mathrm{well})$ and incubation for $4 \mathrm{~h}$ at $37^{\circ} \mathrm{C}$. The medium was subsequently discarded from each well where the formazan crystals were dissolved in DMSO. Absorbance was measured at $570 \mathrm{~nm}$ using a SpectraMax M5 Plate reader (Molecular Devices, LLC). All experiments were performed in triplicate. The IC50 of each group was measured using an IC50 Calculator (https://www. aatbio.com/tools/ic50-calculator/).

Statistical analysis. Each experiment was reproduced at least three times with consistent results. Pairwise comparisons were made using Student's t-test or a non-parametric U Mann-Whitney test using the SPSS version 18.0 (SPSS, Inc.) and Microsoft Excel Office 2011 (Microsoft Corporation) softwares. Multiple group analyses were performed using one-way ANOVA followed by Tukey's post hoc test. $\mathrm{P}<0.05$ was considered to indicate a statistically significant difference.

\section{Results}

Eugenol increases the concentration of Nrf2 proteins and its transcriptional activity. Nrf2 serves an important role in protective responses against oxidative stress $(16,17)$. Therefore, for the present study, the effect of eugenol and its derivatives, methyleugenol and acetyleugenol (Fig. 1), on the expression of Nrf2 and its transcriptional activity on target gene transcription were investigated in HEK-293 cells and the mouse fibroblast cell line NIH-3T3. Luciferase reporter assay based on plasmids containing ARE, a putative Nrf2-responsive cis-acting element, revealed that transcriptional activity of $\mathrm{Nrf} 2$ was significantly increased in both HEK-293 and NIH-3T3 cells treated with eugenol compared with control vehicle cells treated with DMSO (Fig. 2A); with dose-dependency observed for HEK-293 cells. However, no significant differences in Nrf2 transcriptional activity were observed between acetyleugenol-treated and control groups (Fig. 2A and B). For methyleugenol treatment, it appears to be weaker than eugenol in HEK-293 cells but similar to eugenol at high doses; but had no effect on $3 \mathrm{~T} 3$ cells.

To verify the effect of these three eugenol derivatives on Nrf2-mediated transcription further, RT-qPCR was performed on HEK-293 cells to determine the expression levels of target genes downstream of Nrf2 activation (GCL-M, GSTA1 and NFE2L2). Of the three eugenol derivatives tested, only 
A

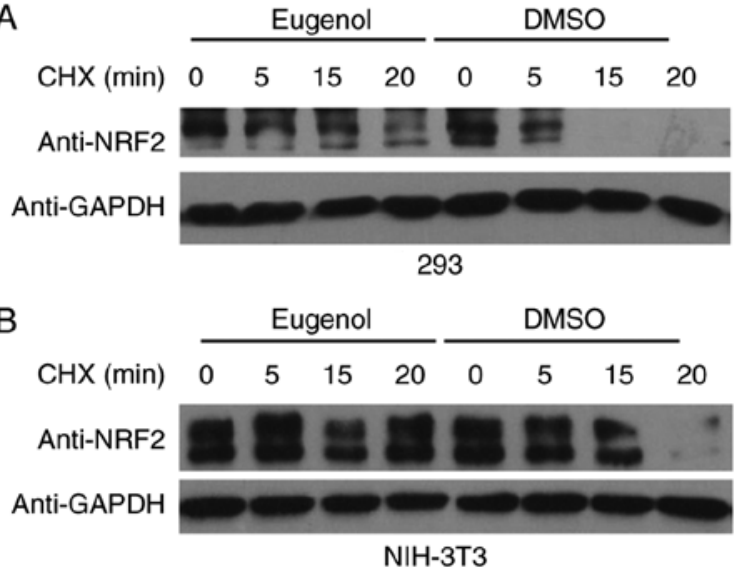

Figure 5. Eugenol stabilizes Nrf2 protein in 293 and 3T3 cells. (A) 293 cells were first transfected with a plasmid expressing Nrf2 (pcDNA3.1-Nrf2) before $6 \mathrm{~h}$ treatment with $50 \mu \mathrm{g} / \mathrm{ml}$ eugenol. (B) Identical experiment was performed on NIH-3T3 cells, but with $100 \mu \mathrm{g} / \mathrm{ml}$ eugenol. Following CHX $(20 \mu \mathrm{g} / \mathrm{ml})$ treatment, the level of Nrf2 protein expression was evaluated at the indicated time points by western blotting. Experiments were performed in triplicate. Nrf2, nuclear factor erythroid 2-related factor 2; CHX, cycloheximide

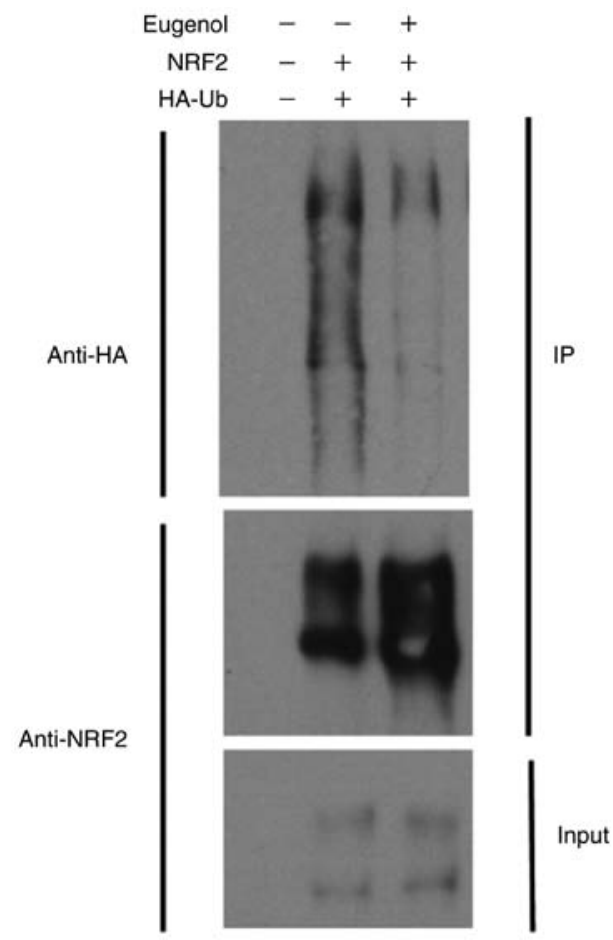

Figure 6. Eugenol inhibits Nrf2 ubiquitination in 293 cells. Plasmids expressing Nrf2 and HA-Ub were first co-transfected into 293 cells for $24 \mathrm{~h}$. Cells were subsequently treated with MG132 $(2 \mu \mathrm{M})$ in the absence or presence of eugenol $(50 \mu \mathrm{g} / \mathrm{ml})$ for $6 \mathrm{~h}$. Whole-cell extracts were prepared and subjected to Nrf2 protein purification using anti-Flag antibody beads. Precipitates were visualized by western blot analysis using anti-HA antibodies. Experiments were performed in triplicate. Nrf2, nuclear factor erythroid 2-related factor 2; HA, human influenza hemagglutinin; HA-Ub, HA-tagged ubiquitin; IP, immunoprecipitation.

eugenol treatment significantly increased mRNA expression of all three genes tested, whereas treatment with the other two derivatives only elevated one or two of the Nrf2 target genes tested (Fig. 3A-C).

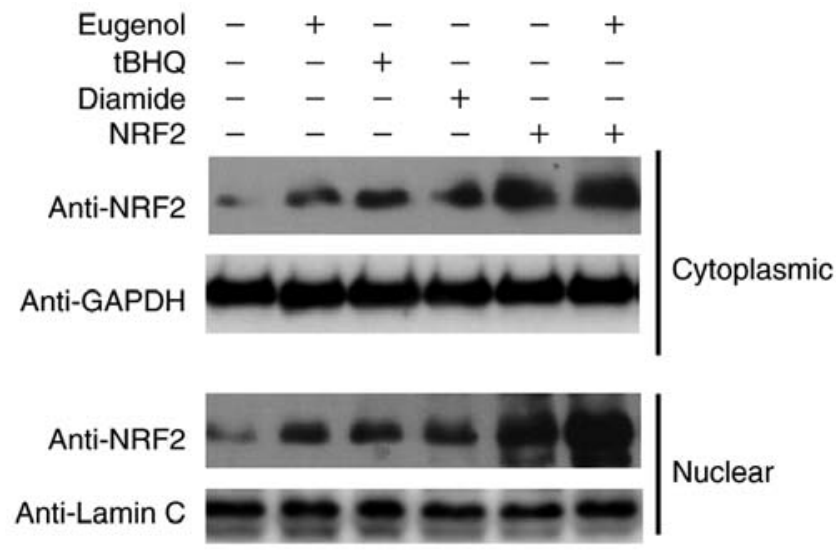

Figure 7. Nrf2 accumulated in the nucleus of in eugenol-treated cells. 293 cells with pcDNA3.1-Nrf2 or empty pcDNA3.1 plasmid were treated with eugenol $(50 \mu \mathrm{g} / \mathrm{ml})$, tBHQ $(100 \mu \mathrm{g} / \mathrm{ml})$ or Diamide $(20 \mu \mathrm{g} / \mathrm{ml})$ for $6 \mathrm{~h}$. Western blot analysis was subsequently performed to measure Nrf2 protein levels in cytoplasmic and nuclear fractions. GAPDH and Lamin C were applied as loading controls for cytoplasmic and nuclear proteins, respectively. Experiments were performed in triplicate. Nrf2, nuclear factor erythroid 2-related factor 2; tBHQ, tert-butylhydroquinone.

Western blotting revealed that the expression levels of Nrf2 protein were increased by treatment with eugenol, but not with the other two derivatives in HEK-293 cells (Fig. 4A). Similar observations were obtained in NIH-3T3 cells (Fig. 4B). These data suggest that eugenol can promote the expression and transcriptional activity of Nrf2 in HEK-293 and NIH-3T3 cells.

Eugenol stabilizes Nrf2 and increases its nuclear accumulation. To explore the molecular mechanism underlying the effect of eugenol on Nrf2, changes in the stability of Nrf2 following exposure to eugenol were tested. Nrf2 proteins persisted for markedly longer in the presence of eugenol in both 293 (Fig. 5A) and NIH-3T3 cells (Fig. 5B). Ubiquitination assay also showed that Nrf2 ubiquitination was markedly reduced following treatment with eugenol (Fig. 6). Samples without UB and NRF2 plasmid transfection acted as a negative control.

Subsequently, further western blotting was performed to assess Nrf2 expression in the cytosol and nucleus of 293 cells. Diamide and tBHQ was reported to increase NRF2 protein expression (15). The nuclear and cytoplasmic content of Nrf2 was found to be markedly increased following treatment with eugenol (Fig. 7). Taken together, these observations suggest that eugenol was able to induce the stabilization and nuclear accumulation of Nrf2.

Eugenol protects cells against $\mathrm{H}_{2} \mathrm{O}_{2}$-induced oxidative damage. To investigate the effects of eugenol on oxidative stress, DCF assays were conducted on 293 cells, which were loaded with the ROS-sensitive dye CM-H2DCFDA following eugenol treatment. After exposure to $\mathrm{H}_{2} \mathrm{O}_{2}$, cells treated with eugenol exhibited significantly lower intracellular ROS levels compared with mock cells (Fig. 8).

MTT assay was used to assess the protective effects of eugenol on $\mathrm{H}_{2} \mathrm{O}_{2}$-treated 293 and 3T3 cells. Eugenol was found to significantly increase cell viability in the presence of $\mathrm{H}_{2} \mathrm{O}_{2}$ (Fig. 9). These results suggest that eugenol protects cells from $\mathrm{H}_{2} \mathrm{O}_{2}$-induced cytotoxicity. 

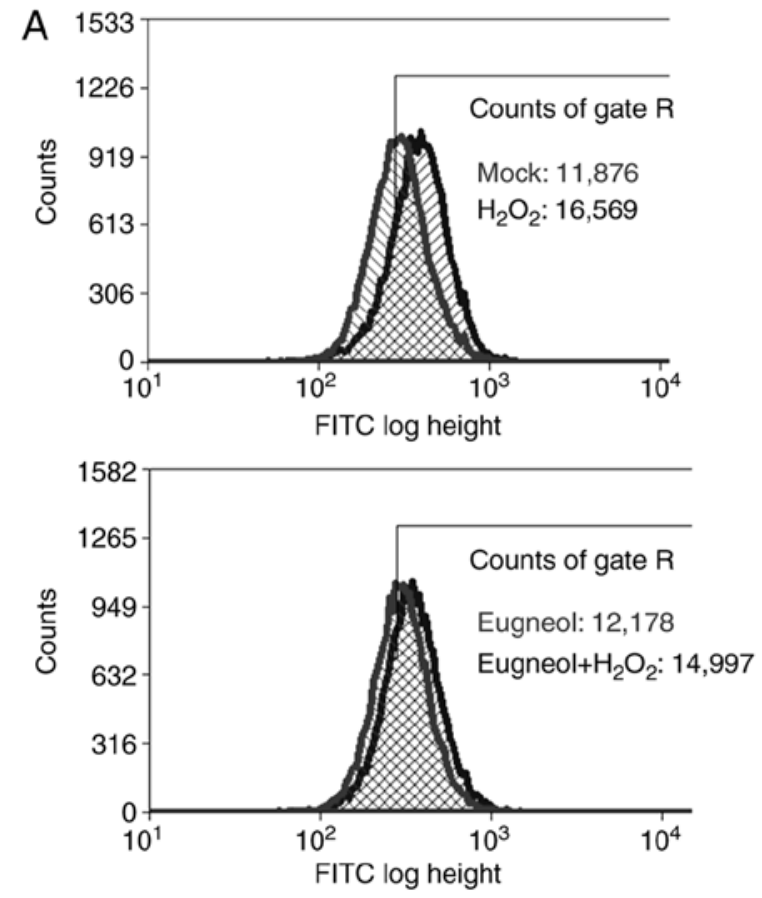

B

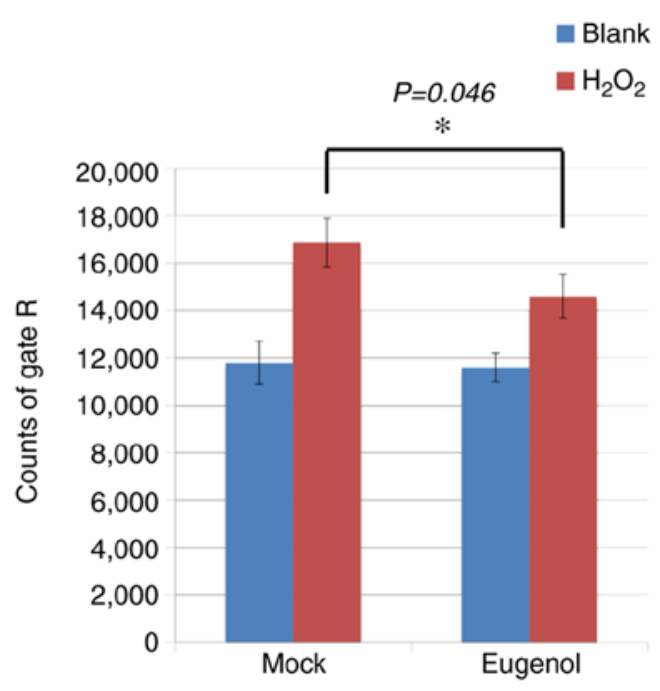

Figure 8. Eugenol protected cells against $\mathrm{H}_{2} \mathrm{O}_{2}$-induced oxidative damage. (A) 293 cells were treated with or without $50 \mu \mathrm{g} / \mathrm{ml}$ eugenol for $24 \mathrm{~h}$. Subsequently, $10 \mu \mathrm{M}$ CM-H2DCFDA was loaded into the cells with or without $50 \mu \mathrm{M} \mathrm{H}_{2} \mathrm{O}_{2}$. DCF assay was performed followed by flow cytometry analysis. (B) Quantified data of (A), with data presented as the mean \pm SD of counts in gates R. Experiments were performed in triplicate. " $\mathrm{P}<0.05$. DCF, 2',7'-dichlorofluorescein; CM-H2DCFDA, 2',7'-dichlorodihydrofluorescein diacetate.

A

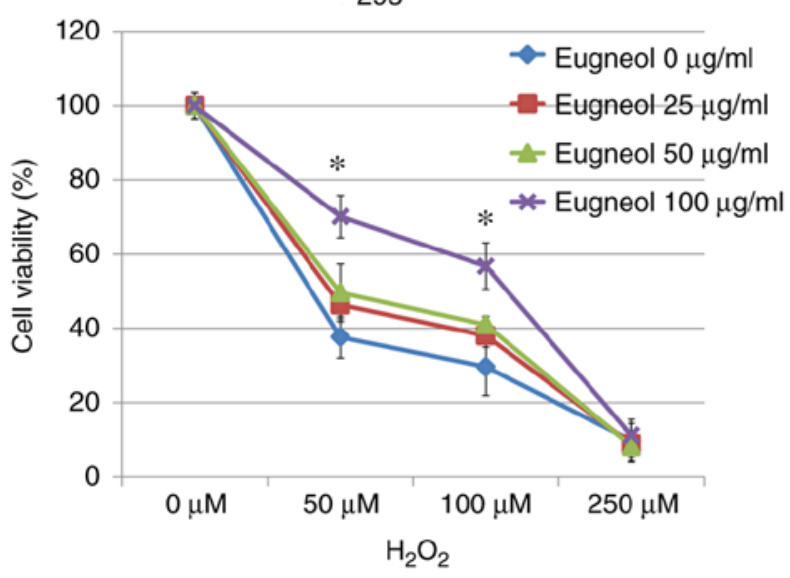

B

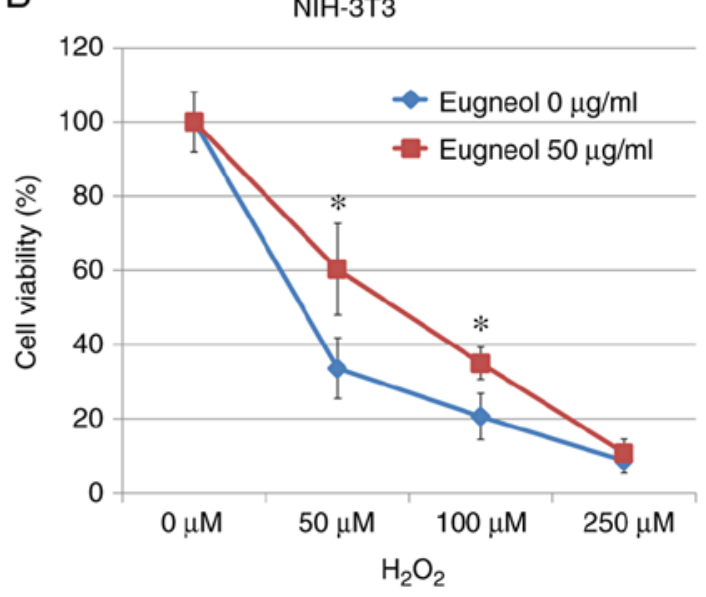

Figure 9. Eugenol enhanced cell survival following exposure to $\mathrm{H}_{2} \mathrm{O}_{2}$. (A) 293 cells were treated with $(0,25,50$ or $100 \mu \mathrm{g} / \mathrm{ml})$ eugenol and $(0,50,100$ or $250 \mu \mathrm{M}$ ) $\mathrm{H}_{2} \mathrm{O}_{2}$ for $24 \mathrm{~h}$, following which MTT assays were performed to measure cell viability. (B) An identical experiment was also performed in NIH-3T3 cells, but with $100 \mu \mathrm{g} / \mathrm{ml}$ eugenol. Experiments were performed in triplicate. Data were presented as mean $\pm \mathrm{SD}$. ${ }^{*} \mathrm{P}<0.05$, eugenol $100 \mu \mathrm{g} / \mathrm{ml}$ vs. eugenol $0 \mu \mathrm{g} / \mathrm{ml}$.

Nrf2 induction is required for the protective effects of eugenol on cells against oxidative stress. To study the role of increased Nrf2 expression and transcriptional activity in the enhanced cell viability induced by eugenol, Nrf2 expression was knocked down using plasmids expressing short hairpin RNA (Fig. 11A). Nrf2 knockdown significantly abrogated the protective effects of eugenol on HEK-293 and 3T3 cells following exposure to $\mathrm{H}_{2} \mathrm{O}_{2}$ (Fig. 10). In addition, western blot analysis of cleaved caspase-3, a key regulator of apoptosis, suggested that eugenol treatment abolished the pro-apoptotic activity of $\mathrm{H}_{2} \mathrm{O}_{2}$ on HEK-293 and 3T3 cells, as evidenced by reduced levels of cleaved caspase- 3 in cells transfected with shControl after $\mathrm{H}_{2} \mathrm{O}_{2}$ treatment. However, the expression levels of cleaved Caspase-3 after exposure to $\mathrm{H}_{2} \mathrm{O}_{2}$ was not affected by eugenol treatment following Nrf2 knockdown (Fig. 11B). These results suggest that increased $\mathrm{Nrf} 2$ expression is required for the protective effects of eugenol on $\mathrm{H}_{2} \mathrm{O}_{2}$-induced oxidative stress.

\section{Discussion}

The present study revealed that the transcriptional activity and expression of $\mathrm{Nrf} 2$ is increased by the eugenol treatment, 

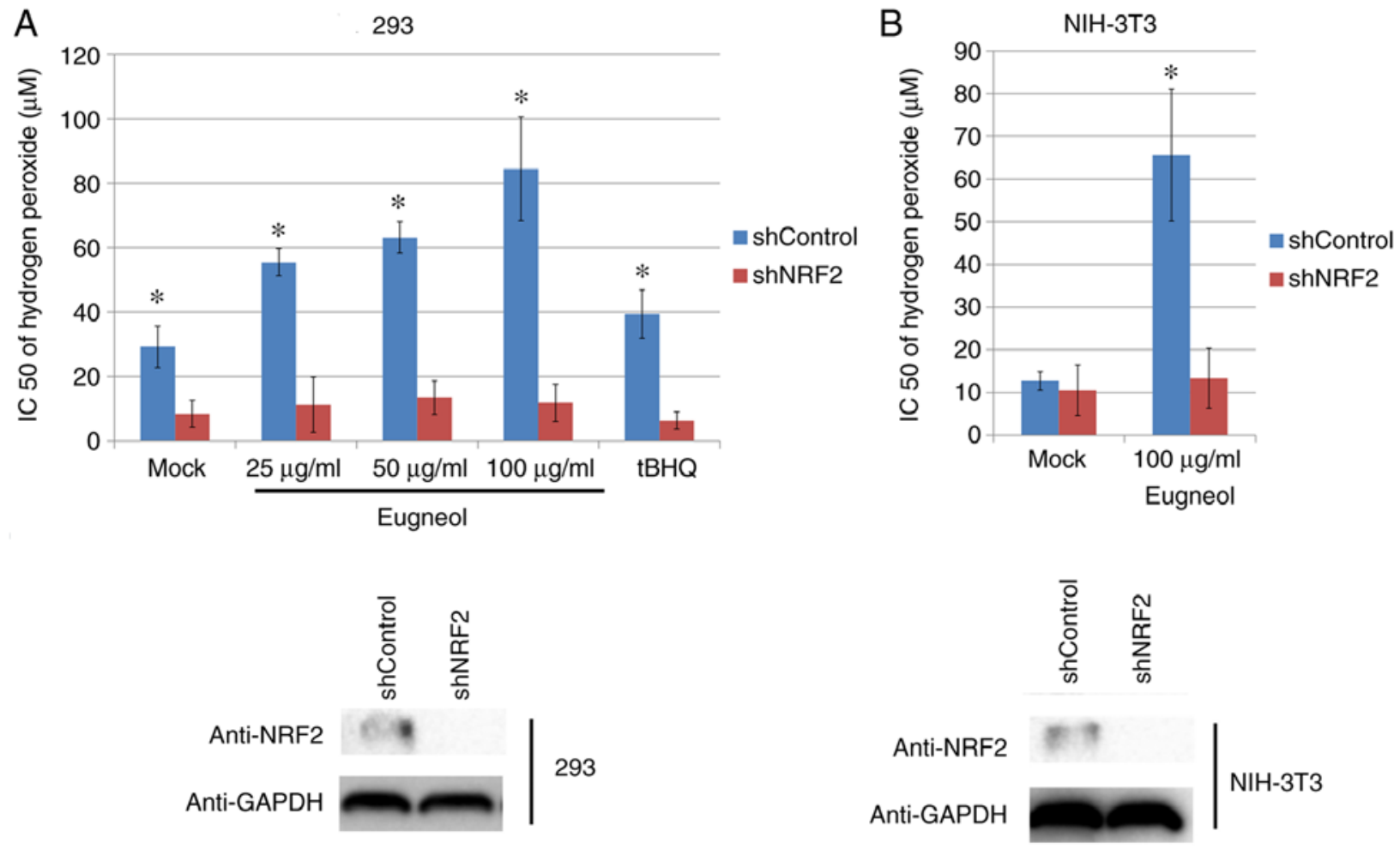

Figure 10. Nrf2 knockdown abolished the protective effects of eugenol on $\mathrm{H}_{2} \mathrm{O}_{2}$-induced damage. (A) The HEK-293 cells transfected with plasmids expressing shNRF2 or shControl were treated with eugenol $(0,25,50$ or $100 \mu \mathrm{g} / \mathrm{ml})$ and $\mathrm{H}_{2} \mathrm{O}_{2}(0,50,100$ or $250 \mu \mathrm{M})$ for $24 \mathrm{~h}$, following which MTT assays were performed to measure cell viability. (B) An identical experiment was also performed in NIH-3T3 cells but with $100 \mu \mathrm{g} / \mathrm{ml}$ eugenol. The IC50 values were calculated according to the obtained MTT assay data. tBHQ $(100 \mu \mathrm{g} / \mathrm{ml})$ was used as positive control. Experiments were performed in triplicate. Data were presented as mean $\pm \mathrm{SD}$. ${ }^{*} \mathrm{P}<0.05$ vs. shNRF2. Nrf2, nuclear factor erythroid 2-related factor 2; tBHQ, tert-butylhydroquinone; sh, short hairpin RNA.

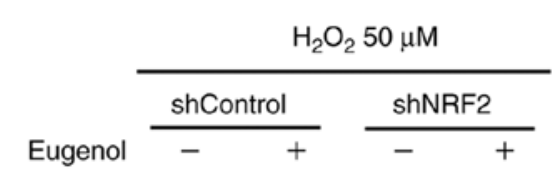

Anti-cleaved caspase-

Anti-NRF

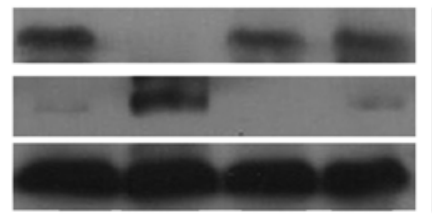

293

Anti-GAPDH

Anti-cleaved caspase-3

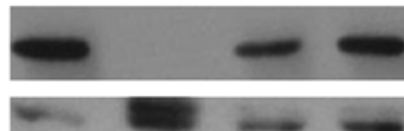

Anti-NRF

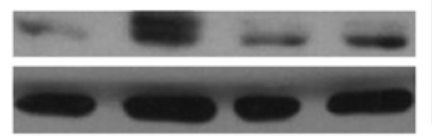

NIH-3T3

Anti-GAPDH

Figure 11. Nrf2 knockdown abrogates the protective effects of eugenol on $\mathrm{H}_{2} \mathrm{O}_{2}$-induced apoptosis. 293 and NIH-3T3 cells transfected with either shNRF2 or shControl were treated with eugenol $(100 \mu \mathrm{g} / \mathrm{ml})$ and $\mathrm{H}_{2} \mathrm{O}_{2}$ $(50 \mu \mathrm{M})$ for $24 \mathrm{~h}$, following which western blot analysis was performed to examine the expression level of cleaved-Caspase 3 and Nrf2. Experiments were performed in triplicate. Nrf2, nuclear factor erythroid 2-related factor 2; sh, short hairpin RNA.

resulting in increased expression of target genes. Although the two other derivatives of eugenol tested also exerted similar effects on Nrf2 function, their potency appeared to be weaker compared with that of eugenol. This result may be explained by the importance of the hydroxyl group attached to aromatic ring, which may mediate the anti-oxidant properties of eugenol. In the other two derivatives, the hydroxyl group was replaced by methoxyl and acetyl-O groups, respectively. This finding suggests that this hydroxyl group should be preserved in subsequent optimizations of eugenol for the enhancement of bioactivity.

Mechanistically, the present study demonstrated that eugenol increases the expression level and activity of Nrf2 by stabilizing the Nrf2 protein through suppressing ubiquitination. The attachment of ubiquitin to Nrf2 by Kelch-like ECH associated protein 1, an E3 ligase that specifically recognizes $\mathrm{Nrf} 2$, lead to its degradation in a proteasome-dependent manner $(18,19)$. This event is believed to be the major regulatory mechanism upstream of Nrf2 (18). Although the effect of eugenol on Nrf2 levels has been confirmed by the present study, available data remain insufficient to conclude if Keap1 or Nrf2 itself is a target of eugenol, which warrant further study.

A number of molecular mechanisms have been proposed to be associated with the anti-oxidant properties of eugenol. For instance, COX-2 mRNA expression was reduced by eugenol treatment in LPS-stimulated macrophages in a previous study (7), whilst eugenol was reported to sequester hydroxyl radicals in another study in an in vitro system (8). Subsequent experiments in the present study revealed that eugenol treatment can rescue cells from oxidative stress induced by $\mathrm{H}_{2} \mathrm{O}_{2}$ exposure in a Nrf2 dependent manner. The near complete reversal of this protective effect by eugenol on cells by Nrf2 
knockdown suggest that the activation of Nrf2 signaling is a novel mechanism by which eugenol counters against oxidative stress. These data confirmed the pivotal role of Nrf2 signaling in the regulation of cellular Redox systems and further support Nrf2 as a promising target for the development of novel anti-oxidative drugs.

Huang et al (9) previously found that AEE protects vascular endothelial cells from oxidative injury by regulating NOS and Nrf2 signaling pathways, whilst Zhou et al (15) reported that methyleugenol may exhibit a protective role against t-BHP-induced cytotoxicity through the activation of the AMPK/GSK3 $\beta$ - and ERK-Nrf2 signaling pathways. Comparing the present study with these two previous studies aforementioned, the present study revealed that eugenol, but not AEE or methyleugenol, exhibited anti-oxidant properties.

In conclusion, the present study provided evidence that eugenol activates Nrf2 signaling resulting in the protection of cells from damage from oxidative stress. These data elucidated the molecular mechanism underlying the anti-oxidative activity of Nrf2 signaling, supporting the notion that eugenol may be a promising lead compound for the development of novel potent anti-oxidant drugs.

\section{Acknowledgements}

Not applicable.

\section{Funding}

This work was supported by the National Natural Science Foundation of China (grant nos. 81272264, 81172013, 81101505 and 81672926) and Zhejiang Provincial Natural Science Foundation of China (grant no. LQ16C090001).

\section{Availability of data and materials}

The datasets used and/or analyzed during the current study are available from the corresponding author on reasonable request.

\section{Authors' contributions}

LM and YG performed the cell experiments. LM, JL and QL performed the in vitro and in vivo assays. LM and WY designed the study, interpreted the results and wrote and edited the manuscript. All authors read and approved the final manuscript.

\section{Ethics approval and consent to participate}

Not applicable.

\section{Patient consent for publication}

Not applicable.

\section{Competing interests}

The authors declare that they have no competing interests.

\section{References}

1. Kamatou GP, Vermaak I and Viljoen AM: Eugenol--from the remote Maluku Islands to the international market place: A review of a remarkable and versatile molecule. Molecules 17: 6953-6981, 2012.

2. Srinivasan K: Antioxidant potential of spices and their active constituents. Crit Rev Food Sci Nutr 54: 352-372, 2014.

3. Nagashima K: Inhibitory effect of eugenol on $\mathrm{Cu} 2+$-catalyzed lipid peroxidation in human erythrocyte membranes. Int $\mathbf{J}$ Biochem 21: 745-749, 1989.

4. Nagababu E and Lakshmaiah N: Inhibition of microsomal lipid peroxidation and monooxygenase activities by eugenol. Free Radic Res 20: 253-266, 1994.

5. Joe B and Lokesh BR: Role of capsaicin, curcumin and dietary n-3 fatty acids in lowering the generation of reactive oxygen species in rat peritoneal macrophages. Biochim Biophys Acta 1224: 255-263, 1994.

6. Jaganathan SK and Supriyanto E: Antiproliferative and molecular mechanism of eugenol-induced apoptosis in cancer cells. Molecules 17: 6290-6304, 2012.

7. Kim SS, Oh OJ, Min HY, Park EJ, Kim Y, Park HJ, Nam Han Y and Lee SK: Eugenol suppresses cyclooxygenase-2 expression in lipopolysaccharide-stimulated mouse macrophage RAW264.7 cells. Life Sci 73: 337-348, 2003.

8. Ogata M, Kaneya D, Shin-Ya K, Li L, Abe Y, Katoh H, Seki S, Seki Y, Gonda R, Urano S, et al: Trapping effect of eugenol on hydroxyl radicals induced by L-DOPA in vitro. Chem Pharm Bull (Tokyo) 53: 1167-1170, 2005.

9. Huang MZ, Yang YJ, Liu XW, Qin Z and Li JY: Aspirin eugenol ester attenuates oxidative injury of vascular endothelial cells by regulating NOS and Nrf2 signalling pathways. Br J Pharmacol 176: 906-918, 2019.

10. Gold R, Kappos L, Arnold DL, Bar-Or A, Giovannoni G, Selmaj K, Tornatore C, Sweetser MT, Yang M, Sheikh SI, et al; DEFINE Study Investigators: Placebo-controlled phase 3 study of oral BG-12 for relapsing multiple sclerosis. N Engl J Med 367: 1098-1107, 2012.

11. Niture SK, Khatri R and Jaiswal AK: Regulation of Nrf2-an update. Free Radic Biol Med 66: 36-44, 2014.

12. Kumar H, Kim IS, More SV, Kim BW and Choi DK: Natural product-derived pharmacological modulators of Nrf2/ARE pathway for chronic diseases. Nat Prod Rep 31: 109-139, 2014.

13. Xie Y, Zhao QY, Li HY, Zhou X, Liu Y and Zhang H: Curcumin ameliorates cognitive deficits heavy ion irradiation-induced learning and memory deficits through enhancing of Nrf2 antioxidant signaling pathways. Pharmacol Biochem Behav 126: 181-186, 2014.

14. Lu YF, Liu J, Wu KC and Klaassen CD: Protection against phalloidin-induced liver injury by oleanolic acid involves Nrf 2 activation and suppression of Oatp1b2. Toxicol Lett 232: 326-332, 2015.

15. Zhou J, Ma X, Cui Y, Song Y, Yao L, Liu Y and Li S: Methyleugenol protects against t-BHP-triggered oxidative injury by induction of Nrf2 dependent on AMPK/GSK $3 \beta$ and ERK activation. J Pharmacol Sci 135: 55-63, 2017.

16. Miltenberger RJ, Cortner J and Farnham PJ: An inhibitory Raf-1 mutant suppresses expression of a subset of v-raf-activated genes. J Biol Chem 268: 15674-15680, 1993.

17. Wasserman WW and Fahl WE: Functional antioxidant responsive elements. Proc Natl Acad Sci USA 94: 5361-5366, 1997.

18. Jaramillo MC and Zhang DD: The emerging role of the Nrf2-Keap1 signaling pathway in cancer. Genes Dev 27: 2179-2191, 2013.

19. Liu J, Shaik S, Dai X, Wu Q, Zhou X, Wang Z and Wei W: Targeting the ubiquitin pathway for cancer treatment. Biochim Biophys Acta 1855: 50-60, 2015. 